\title{
DEVELOPMENT OF PHYSIOLOGICALLY BASED PHARMACOKINETIC MODEL FOR THE IMMEDIATE RELEASE ROPINIROLE TABLETS
}

\author{
OLHA SHUKLINOVA ${ }^{1 * \#}$, PRZEMYSŁAW DOROŻYŃSKI ${ }^{3}$, PIOTR KULINOWSKI $^{4}$, \\ ZOFIA M. BIELECKA ${ }^{1,2}$, BARBARA WIŚNIOWSKA ${ }^{1}$, and SEBASTIAN POLAK ${ }^{1,2}$
}

${ }^{1}$ Faculty of Pharmacy, Jagiellonian University Medical College, Medyczna 9 Street, 30-688 Kraków, Poland

${ }^{2}$ Simcyp Division, Certara UK Limited, Level 2-Acero, 1 Concourse Way, Sheffield, S1 2BJ, UK

${ }^{3}$ Department of Drug Technology and Pharmaceutical Biotechnology, Medical University of Warsaw,

Banacha 1, 02-097 Warszawa, Poland

${ }^{4}$ Pedagogical University of Cracow, Institute of Technology, Podchorążych 2, 30-084 Kraków, Poland

\begin{abstract}
Ropinirole is a dopamine receptor agonist with high inter-individual variability in pharmacokinetic parameters. Physiologically based pharmacokinetic (PBPK) modeling allows predicting drug pharmacokinetic behavior while accounting for individual demographic and physiological parameters. Considering that ropinirole is used in patients of different ages and disease states, a PBPK model could be of potential use in informing clinical trials or new formulation development. The aim of this study was to develop a PBPK model for ropinirole and investigate whether the developed model will be able to predict pharmacokinetics in patient populations. Within this paper, a PBPK model for the immediate release ropinirole tablets was developed and verified against observed data from 11 clinical trials. The model reasonably predicted pharmacokinetics of ropinirole in healthy volunteers and patient populations. Predicted ropinirole PK parameters were within 2-fold of the observed values. The model is able to predict ropinirole pharmacokinetics in healthy volunteers, Parkinson's disease patients, and restless legs syndrome patients.
\end{abstract}

Keywords: ropinirole, physiologically based pharmacokinetic modeling, Parkinson's disease

Ropinirole is a non-ergoline $\mathrm{D}_{2}$-like receptor agonist indicated for the treatment of signs and symptoms of PARKD both in combination with levodopa/carbidopa and as monotherapy $(1,2)$. The drug is also used for the symptomatic treatment of restless legs syndrome (RLS) $(3,4)$ and currently is studied as the potential candidate for amyotrophic lateral sclerosis $(5,6)$. In addition, ropinirole pharmacokinetic and pharmacodynamic properties were characterized in patients with prolactinomas (7). The drug is administered orally with subsequent full and rapid absorption when given as an immediate release (IR) formulation (8). The compound is extensively metabolized in the liver primarily by CYP1A2 and with much lesser involvement of CYP3A4. 10\% of the dose is excreted in the urine in unchanged form (9). None of the ropinirole metabolites with high affinity to the $\mathrm{D}_{2}$ and $\mathrm{D}_{3}$ receptors in vitro has demonstrated significant pharmacological activity in vivo $(8,10)$. The absolute bioavailability established for the immediate release tablets in healthy volunteers
(HV) is $55 \%$ (11). The pharmacokinetic (PK) behavior of the drug is dose-proportional $(12,13)$ and its dose-dependent activity has been also demonstrated (14). Ropinirole treatment is started from the low dose ( $0.25 \mathrm{mg}$ TID) with a gradual increase based on clinical observations for each patient. Such a dosing pattern is aimed at suppressing disease symptoms while reducing peripheral dopaminergic adverse effects of the drug such as nausea, vomiting, or orthostatic hypotension (15). Therefore, the wide strength range of ropinirole from $0.25 \mathrm{mg}$ to $5 \mathrm{mg}$ is anticipated for an IR- and from $2 \mathrm{mg}$ to $12 \mathrm{mg}$ for a modified release drug which allows flexible dose adjustments, when needed $(16,17)$.

In addition to multiple dosing schemas due to ropinirole's pharmacodynamics/safety variability, significant inter-subject variability of ropinirole plasma concentrations has been observed both in HV and in PARKD population $(2,15,18)$. Therefore, considering the multiple possible scenarios of drug exposure in each patient together with

* Corresponding author: e-mail: shuklinova@doctoral.uj.edu.pl 
a large number of different strengths of ropinirole, and potential for the development of new formulations, a physiologically based pharmacokinetic (PBPK) model can be a useful tool for gaining an insight into ropinirole pharmacokinetics in different populations or defining a design space for new formulations.

PBPK helps to understand a drug's pharmacokinetic behavior and its components such as absorption, distribution, metabolism, and elimination with more details $(19,20)$. The structure of PBPK, namely, the separation of the parameters into drug-specific, system-specific, and the trial design $(21,22)$, allows exploring the number of different scenarios regarding the different doses and formulations, concomitantly taken food and/or drugs. Finally, once having a properly verified PBPK model in healthy volunteers, it can be used in order to extrapolate further to the disease population while investigating what pathophysiological parameters can affect the drug's pharmacokinetics (19).

The aim of this study was to develop a PBPK model for an immediate release ropinirole tablets in healthy volunteers and investigate whether the model will capture the clinical data for PARKD/ RLS patients. Since no PBPK model for ropinirole was published yet, the simplest immediate release formulation was chosen as the first step in modeling in order to confirm ropinirole's primary pharmacokinetic parameters.

\section{METHODS}

For modeling and simulation purposes, Simcyp $^{\circledR}$ Simulator (V.19, Certara, Sheffield, UK) was used. Ropinirole compound file was newly developed based on the published physicochemical, in vitro experiments, and in vivo studies data. PK or physicochemical parameters that did not have experimental values available were calculated using suitable tools built into Simcyp Simulator or commonly accepted approaches (inter-species scaling described in the Elimination paragraph). The majority of ropinirole PK parameters and plasma concentrationtime profiles, used for the model verification, were taken from the GlaxoSmithKline (GSK) Clinical
Trial Register (https:/www.gsk-studyregister.com/ en/). Concentration-time profiles data were manually digitalized with the use of GetData Graph Digitizer when needed (http://getdata-graph-digitizer.com/). The clinical data were available for 3 groups of subjects: 1) HV, 2) PARKD patients, and 3) RLS patients. The simulations however were conducted in healthy virtual individuals only which were randomly selected from the available Simcyp population libraries. The list of populations is provided in Table 2 and Table 3. Each trial was simulated 10 times in order to represent conditions of interindividual variability.

\section{Absorption}

In the First-Order Absorption Model, which is available within Simcyp, the gut is treated as one compartment where the absorption process is driven by a single first-order absorption rate constant (ka), and the oral dose is scaled by the fraction absorbed (fa). The model was chosen based on rapid release, dissolution, and absorption of the ropinirole ensured by its high permeability and solubility, which are not influenced by the formulation $(16,23)$. Rapid release/ absorption is additionally confirmed by a relatively small Tmax for IR formulation (please see Table 2 and Table 3 for the details). Based on the literature findings, we have assumed that the drug's dose taken will be fully absorbed (fa $\sim$ ) and that the absorption process will not be affected to a significant extent by the intestinal enzymes and transporters (8, 16). ka was estimated by fitting a pharmacokinetic model to ropinirole plasma concentrations observed in $\mathrm{HV}$ after a single dose of $0.5 \mathrm{mg}$ using Simcyp Parameter Estimation (PE) module and a dataset from a GSK study No. 101468/197 (18). The parameters and values for the optimization procedure are shown in Table 1.
\end{abstract}

\section{Distribution}

Ropinirole is a lipophilic amine and according to the clinical data is extensively distributed beyond the vascular compartment (2). Based on this information, the full PBPK model was chosen with perfusion-limited distribution, which describes the drug movement through the number of

Table 1. Input parameters for ropinirole PBPK model development.

\begin{tabular}{|c|c|c|c|}
\hline Parameter & Description & Value & Reference \\
\hline \multicolumn{4}{|c|}{ Ropinirole physicochemical properties and blood binding } \\
\hline $\mathrm{MW}(\mathrm{g} / \mathrm{mol})$ & Molecular weight & 260.38 & Chemicalize.com \\
\hline $\log \mathrm{P}_{\text {o:w }}$ & $\begin{array}{c}\text { Neutral species octanol: } \\
\text { buffer partition coefficient }\end{array}$ & 2.7 & $(30)$ \\
\hline
\end{tabular}


Table 1. Input parameters for ropinirole PBPK model development (continue).

\begin{tabular}{|c|c|c|c|}
\hline Parameter & Description & Value & Reference \\
\hline Type of the compound & & \multicolumn{2}{|c|}{ Monoprotic base } \\
\hline $\mathrm{pKa}$ & Dissociation constant & 9.79 & (31) \\
\hline $\mathrm{B} / \mathrm{P}$ & $\begin{array}{c}\text { Blood-to-plasma partition } \\
\text { ratio }\end{array}$ & 1.09 & $(32)$ \\
\hline $\mathrm{fu}$ & Fraction unbound in plasma & 0.68 & $(32)$ \\
\hline Absorption model & \multicolumn{3}{|c|}{ First-Order Absorption Model } \\
\hline fa & $\begin{array}{c}\text { Fraction available from } \\
\text { a dosage form }\end{array}$ & 1 & $\begin{array}{l}\text { Assumed, please see the } \\
\text { body text for the details }\end{array}$ \\
\hline $\mathrm{ka}\left(\mathrm{h}^{-1}\right)$ & $\begin{array}{l}\text { First-order absorption rate } \\
\text { constant }\end{array}$ & 0.31 & $\begin{array}{c}\text { Estimated using Simcyp }{ }^{\circledR} \\
\text { PE module }\end{array}$ \\
\hline Distribution Model & \multicolumn{3}{|c|}{ Full PBPK } \\
\hline $\mathrm{V}_{\mathrm{ss}}(\mathrm{L} / \mathrm{kg})$ & $\begin{array}{l}\text { Volume of distribution at } \\
\text { steady state }\end{array}$ & 3.37 & $\begin{array}{l}\text { Simcyp }^{\circledR} \text { predicted } \\
\text { Method } 2\end{array}$ \\
\hline \multicolumn{4}{|l|}{ Elimination } \\
\hline $\mathrm{CL}_{\mathrm{IV}}(\mathrm{L} / \mathrm{h})$ & Human systemic clearance & 42.62 & $\begin{array}{l}\text { Simple allometric scaling } \\
\text { using data for the three } \\
\text { species }\end{array}$ \\
\hline Species & Bodyweight (kg) & $\mathrm{CL}_{\mathrm{IV}}(\mathrm{L} / \mathrm{h} / \mathrm{kg})$ & \\
\hline Wistar rats & 0.24 & 3.3 & (8) \\
\hline Cynomolgus monkeys & 4.50 & 1.4 & $(8)$ \\
\hline Beagle dogs & $12 *$ & 1.02 & (33) \\
\hline \multicolumn{4}{|c|}{ Enzyme kinetic parameters for IVIVE } \\
\hline$N$-despropylation & Enzyme & Value & \\
\hline $\mathrm{V}_{\max }(\mathrm{nmol} / \mathrm{h} / \mathrm{mg})$ & CYP1A2 & 7.83 & \multirow{9}{*}{ (9) } \\
\hline $\mathrm{K}_{\mathrm{m}}(\mu \mathrm{mol})$ & CYP1A2 & 34.63 & \\
\hline $\mathrm{V}_{\max }(\mathrm{nmol} / \mathrm{h} / \mathrm{mg})$ & CYP3A4 & 523.33 & \\
\hline $\mathrm{K}_{\mathrm{m}}(\mu \mathrm{mol})$ & CYP3A4 & 2700.00 & \\
\hline Hydroxylation & & & \\
\hline $\mathrm{V}_{\max }(\mathrm{nmol} / \mathrm{h} / \mathrm{mg})$ & CYP1A2 & 6.93 & \\
\hline $\mathrm{K}_{\mathrm{m}}(\mu \mathrm{mol})$ & CYP1A2 & 45.87 & \\
\hline $\mathrm{V}_{\max }(\mathrm{nmol} / \mathrm{h} / \mathrm{mg})$ & CYP3A4 & 255.33 & \\
\hline $\mathrm{K}_{\mathrm{m}}(\mu \mathrm{mol})$ & CYP3A4 & 3933.33 & \\
\hline $\mathrm{fu}_{\mathrm{mic}}$ & $\begin{array}{c}\text { Fraction unbound in } \\
\text { an in vitro microsomal } \\
\text { preparation }\end{array}$ & 0.39 & $\begin{array}{l}\text { Estimated based on } \\
\text { a dataset from GSK study } \\
\text { No. } 101468 / 197(18)\end{array}$ \\
\hline \multicolumn{4}{|l|}{$\begin{array}{l}\text { Parameters of the fitting } \\
\text { procedure }\end{array}$} \\
\hline $\begin{array}{c}\text { ka } \\
\text { Initial value (lower bound; } \\
\text { upper bound) }\end{array}$ & $0.5(0.00 ; 2.00)$ & & \\
\hline $\begin{array}{c}\mathrm{fu}_{\mathrm{mic}} \\
\text { Initial value (lower bound; } \\
\text { upper bound) }\end{array}$ & $0.3(0.00 ; 1.00)$ & & \\
\hline Objective function type & $\begin{array}{c}\text { Weighted Least Square } \\
\text { (WLS) }\end{array}$ & & \\
\hline Minimization method & Nelder-Mead & & \\
\hline Max No. of iterations & 100 & & \\
\hline
\end{tabular}

* body weight was taken as a median value from the number of body weights reported in the Yerramilli-Rao and Arther studies $(34,35)$ 
body compartments. The volume of distribution at steady state (Vss) was predicted using Simcyp implemented equation after Sawada et al. (24) that links human physiology data (e.g., plasma, blood, and tissue volume) and tissue/erythrocyte to plasma partition coefficients. Tissue to plasma partition coefficients in turn were predicted using the mechanistic model (Method 2 in Simcyp) after Rodgers and Rowland (25).

\section{Elimination}

The value of ropinirole intravenous systemic clearance for humans $\left(\mathrm{CL}_{\mathrm{IV}}\right)$ was not available in the literature and at the initial stages of model development was obtained by simple allometric scaling from rat, dog, and monkey data with the use of Equation 1 (26-28):

$$
C L_{i}=a \times B W_{i}^{b}
$$

where $C L_{\mathrm{i}}$ - predicted systemic clearance for human $i, a$ and $b$-intercept and the slope of the regression line of systemic clearance vs bodyweight plotted in a log-log scale. $B W i-$ human $i$ body weight.

In order to implement into the PBPK model a more mechanistic description of hepatic clearance and to be able to account for inter-individual variability in metabolic clearance-related physiological parameters, an in vitro - in vivo extrapolation approach was used. The extrapolation was based on enzymespecific kinetic parameters from an in vitro study in human liver microsomes (9). Fraction unbound in microsomal preparation allowing to account for a non-specific binding was not reported in the study and was estimated based on a dataset from a GSK study No. 101468/197 (18) (in the same run with the estimation of $\mathrm{k}_{\mathrm{a}}$ ). The intrinsic metabolic clearance was calculated using the equation (2) implemented into the Simcyp simulator:

$C L_{u H i n t}=\left[\sum \frac{C L_{\text {int }}\left(C Y P_{j}\right)}{f_{\text {umic }, j}} \times C Y P_{j \text { abundance }}\right] \times M P G L \times$ liver weight $\quad$ Eq. 2

where, $\mathrm{CL}_{\text {uHint }}$ - unbound intrinsic hepatic clearance; $\mathrm{CL}_{\text {int(CYPj) }}$ - intrinsic clearance for the $\mathrm{j}$ CYP enzyme, $\mathrm{CYP}_{\text {jabundance }}$ - amount of $\mathrm{j}$ enzyme per mg of microsomal protein in the liver, $\mathrm{fu}_{\text {mic }}$ - fraction unbound in an in-vitro microsomal preparation. It was assumed that there are two reactions in the metabolic pathway of ropinirole ( $\mathrm{N}$-despropylation and hydroxylation) and that to each of the reactions both CYP1A2 and CYP3A4 enzymes are contributing. Subsequently, hepatic clearance was predicted using a well-stirred model (29).
The summary of all model input parameters defining ADME pathways is provided in Table 1.

\section{RESULTS}

The performance of the model was verified by simulating five clinical trials conducted in $\mathrm{HV}$ after oral administration of immediate release tablets. In addition, the studies with RLS patients and PARKD patients were simulated in order to assess whether the model based on the HV population is able to predict ropinirole PK in patients. Trial design parameters such as sample size, gender ratio, age range, dosing regimen in each case were matched with the real clinical conditions, except for patient populations that were not available within the simulation platform. Due to the likelihood of dopaminergic adverse events of ropinirole such as nausea, vomiting, and postural hypotension which are usually more pronounced in healthy volunteers than in patients, in the majority of cases the drug was taken together with the peripherally acting dopamine receptor antagonist domperidone to prevent them. It has been shown that there is no PK interaction between ropinirole and domperidone (36).

Simulated plasma concentration-time profiles and PK parameters such as Cmax, Tmax, AUC for the corresponding time intervals were compared with the observed data. The model performance evaluation was carried out by applying common criteria of predicted PK parameters being within 2 -fold of observed values. Simulated plasma concentration-time profiles were also visually compared with the observed profiles. The detailed information about the simulated studies and predicted to observed ratios are provided in Table 2 (virtual HV vs real HV) and Table 3 (virtual healthy subjects vs. PARKD/RLS patients). One additional study (GSK Study 101468/218) had a specific design therefore it is presented separately with the comparison based on a visual check only (37). The trial design parameters for this study were as follows: 8 RLS patients aged $27-67$ years old administered ropinirole starting from $0.25 \mathrm{mg}$ and up titrating to $4 \mathrm{mg}$. The simulated versus observed ropinirole concentrationtime profiles for all studies are provided in Figure 1. Analysis of the fold difference values together with the visual check has confirmed that both the simulated concentration-time profiles and PK parameters of interest were within two-fold of their respective clinically observed values (please see Table 2). The only exception was Tmax for Brefel et al., 1998 study (38) which was out of the aboveindicated range. 

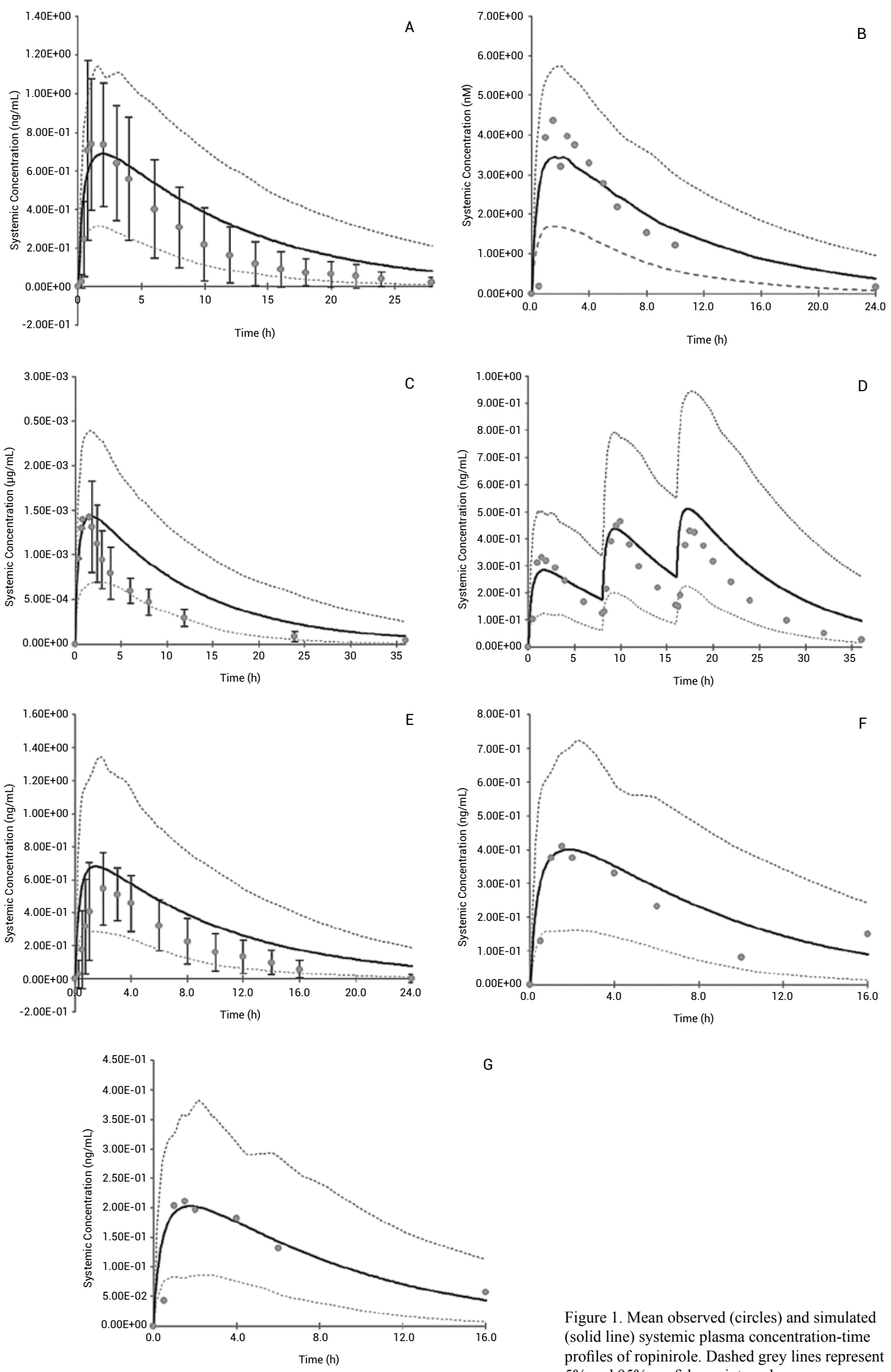

Figure 1. Mean observed (circles) and simulated (solid line) systemic plasma concentration-time profiles of ropinirole. Dashed grey lines represent $5 \%$ and $95 \%$ confidence intervals. 

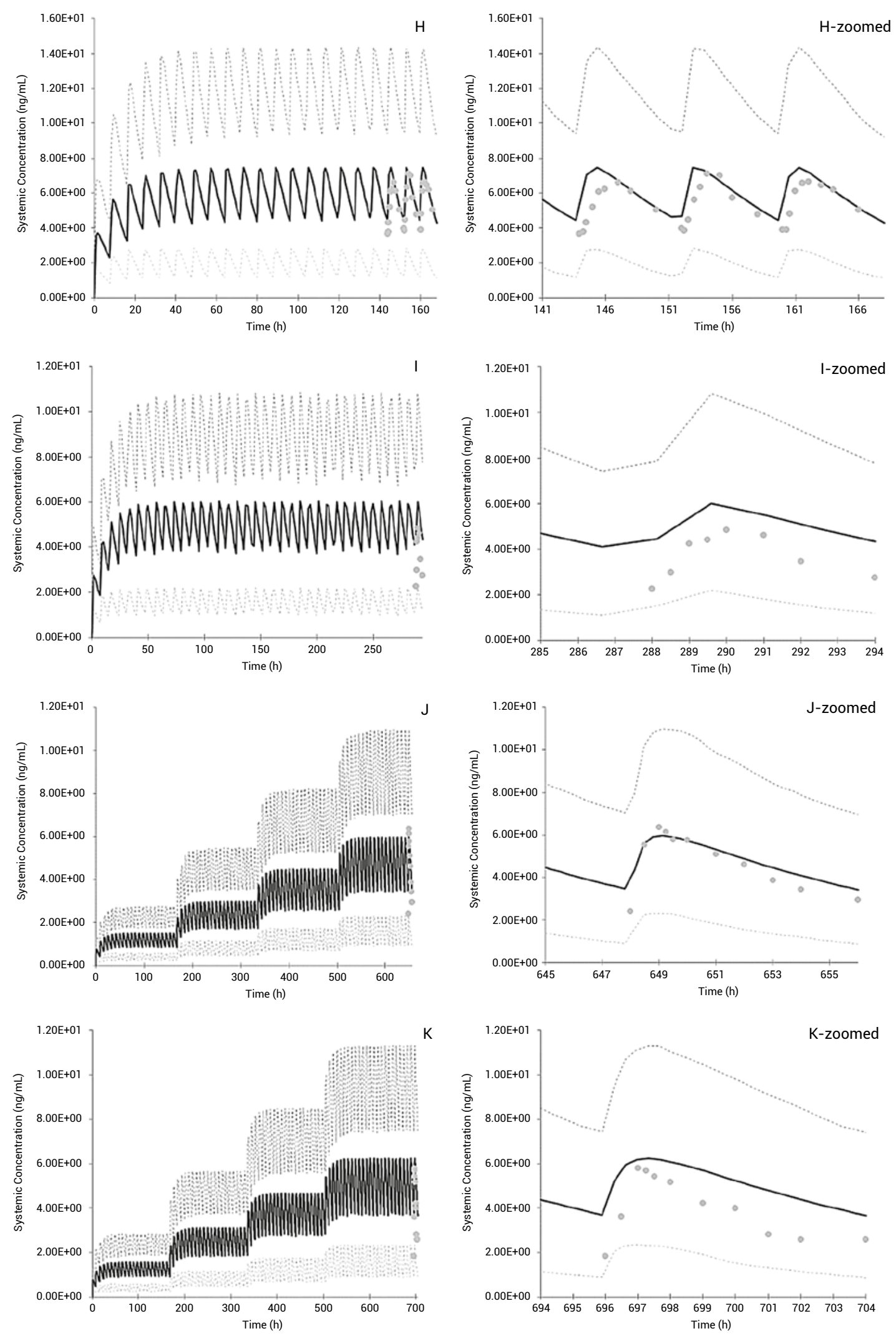

Figure 1. Mean observed (circles) and simulated (solid line) systemic plasma concentration-time profiles of ropinirole. Dashed grey lines represent $5 \%$ and $95 \%$ confidence intervals (continued). 

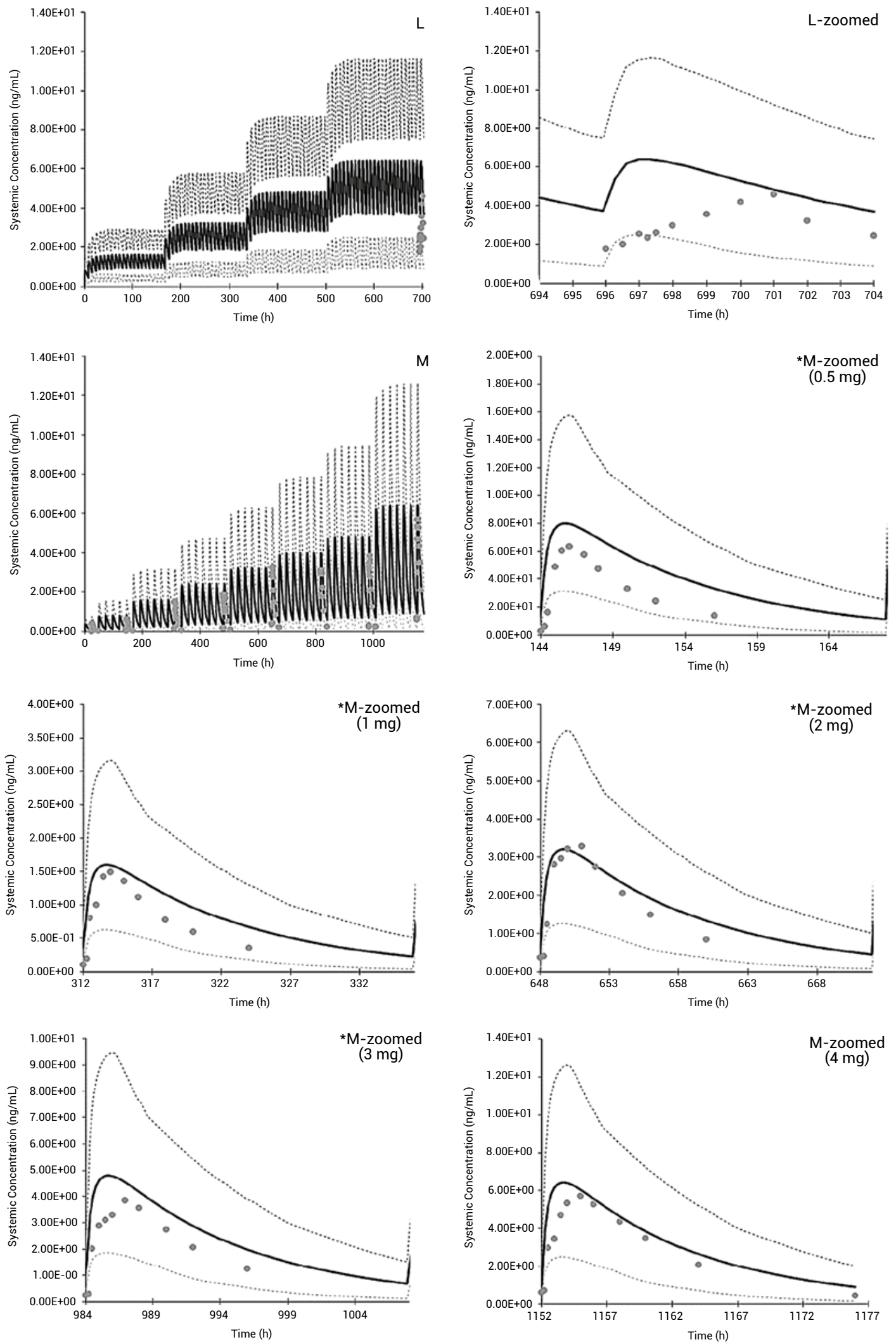

*Please note $\mathrm{X}$ axis range modification

Figure 1. Mean observed (circles) and simulated (solid line) systemic plasma concentration-time profiles of ropinirole. Dashed grey lines represent $5 \%$ and $95 \%$ confidence intervals (continued). 


\begin{tabular}{|c|c|c|c|c|c|c|c|c|c|c|c|c|c|c|c|c|c|c|}
\hline 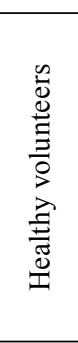 & 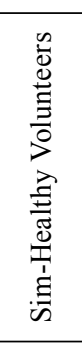 & $\begin{array}{l}\stackrel{\rho}{x} \\
\pm \\
\pm\end{array}$ & 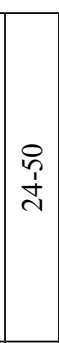 & $\stackrel{+}{\stackrel{+}{\circ}}$ & 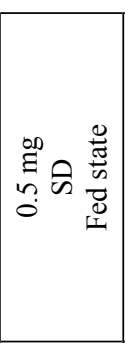 & $\stackrel{?}{\stackrel{9}{-}}$ & ָे & $\begin{array}{l}\tilde{6} \\
0\end{array}$ & $\begin{array}{l}\infty \\
\stackrel{0}{0} \\
\stackrel{0}{0}\end{array}$ & & $\stackrel{8}{\circ}$ & $\begin{array}{cc} & \widehat{G} \\
\hat{y} & : \\
\infty & 0 \\
& \stackrel{0}{e}\end{array}$ & 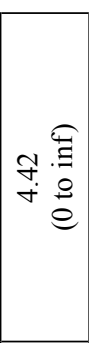 & 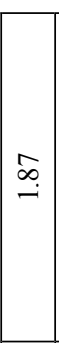 & 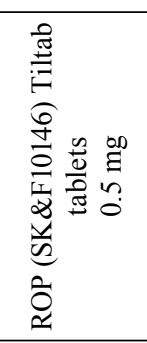 & $\underline{=}$ & $\widehat{Ð}$ & \\
\hline 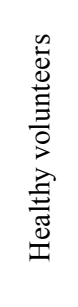 & 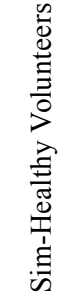 & $\begin{array}{l}\stackrel{0}{x} \\
\pm \\
\pm\end{array}$ & 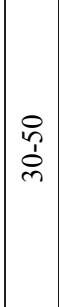 & 0 & 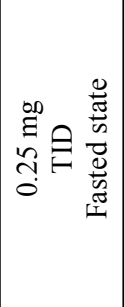 & $\stackrel{+}{-}$ & $\stackrel{\text { 范 }}{-}$ & 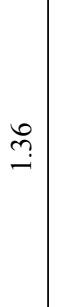 & \begin{tabular}{l}
$\stackrel{P}{f}$ \\
\multirow{0}{*}{}
\end{tabular} & $\begin{array}{l}\mathscr{\infty} \\
\stackrel{\delta}{0} \\
0\end{array}$ & ă & 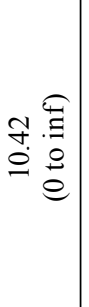 & 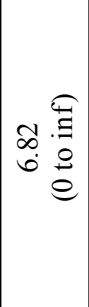 & $\stackrel{n}{n}$ & $\overleftrightarrow{z}$ & $\ominus$ & 高 & \\
\hline 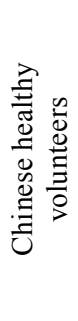 & 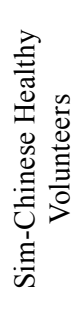 & $\begin{array}{l}0 \\
\underset{x}{a} \\
\underline{y}\end{array}$ & $\mid \begin{array}{l}\infty \\
\stackrel{1}{\sim} \\
\stackrel{\sim}{N}\end{array}$ & $\because$ & 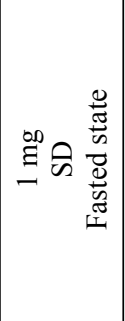 & $\left|\begin{array}{c}0 \\
-\infty \\
-\end{array}\right|$ & $\stackrel{g}{\rightarrow}$ & $\stackrel{m}{\rightarrow}$ & $\underset{\mathscr{P}}{\stackrel{P}{-}}$ & ڤू & б. & $\begin{array}{l}\bar{N} \\
\stackrel{2}{ }\end{array}$ & $\begin{array}{l}\infty \\
\stackrel{0}{\Theta}\end{array}$ & $\stackrel{\infty}{\stackrel{\overbrace{}}{ت}}$ & 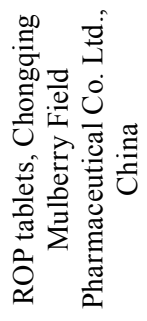 & $\underline{0}$ & ๙્ర & 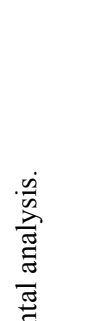 \\
\hline 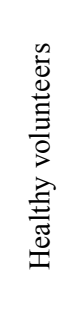 & 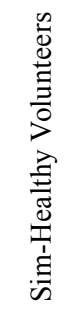 & $\begin{array}{l}\stackrel{\rho}{x} \\
a \\
a\end{array}$ & $\begin{array}{l}\tilde{\tilde{T}} \\
\tilde{\tilde{U}}\end{array}$ & 0 & 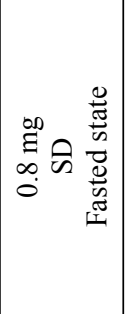 & $\stackrel{\leftrightarrow}{\stackrel{\infty}{-}}$ & 浐 & $\cong$ & $\begin{array}{l}0 \\
\dot{0} \\
0\end{array}$ & . & in & $\begin{array}{l}\hat{m} \\
\stackrel{0}{0}\end{array}$ & ڤ్ & $\stackrel{\text { gे }}{-}$ & 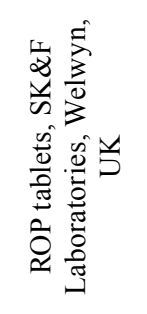 & $\cong$ & $\underset{ర ్ ర ీ}{6}$ & 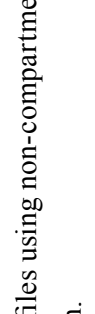 \\
\hline 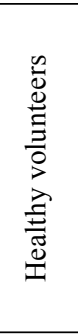 & 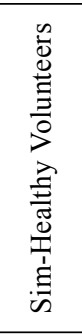 & $\begin{array}{c}\stackrel{\rho}{\vec{x}} \\
\infty \\
\infty\end{array}$ & $\begin{array}{l}F \\
\stackrel{F}{2} \\
\stackrel{2}{2}\end{array}$ & $\stackrel{\overbrace{}}{0}$ & 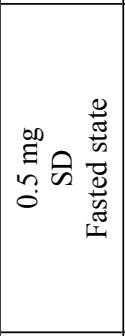 & $\stackrel{\widehat{S}}{S}$ & $\stackrel{f}{ \pm}$ & $\stackrel{m}{\rightarrow}$ & $\begin{array}{l}\stackrel{a}{a} \\
\dot{0} \\
\stackrel{0}{0}\end{array}$ & $\begin{array}{l}\vec{F} \\
0 \\
\dot{0}\end{array}$ & $\begin{array}{l}\widetilde{D} \\
0 \\
0\end{array}$ & $\begin{array}{l}\hat{\alpha} \\
\dot{\alpha} \\
\infty \\
\infty\end{array}$ & 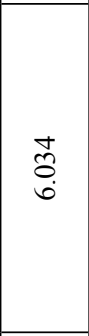 & $\stackrel{f}{\stackrel{f}{-}}$ & 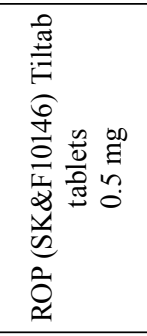 & 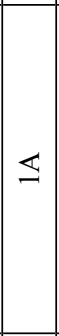 & $\stackrel{*}{\stackrel{*}{\infty}} \underset{\infty}{=}$ & 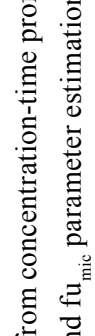 \\
\hline 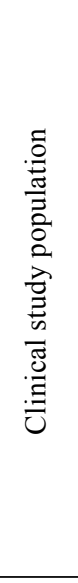 & 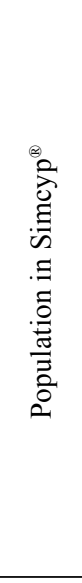 & 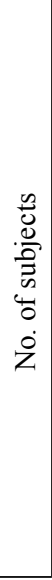 & $\stackrel{8}{8}$ & 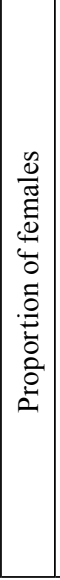 & 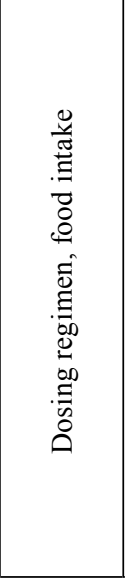 & 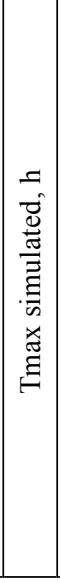 & 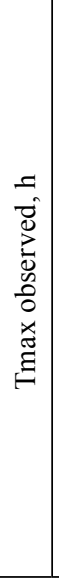 & 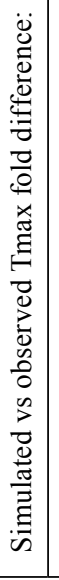 & 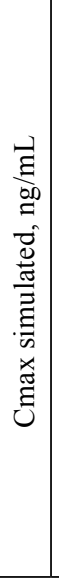 & 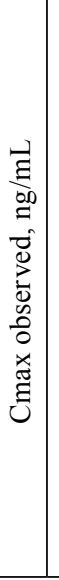 & 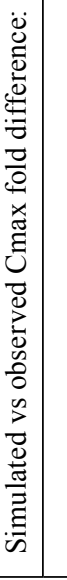 & 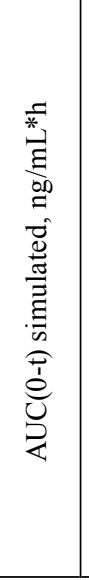 & 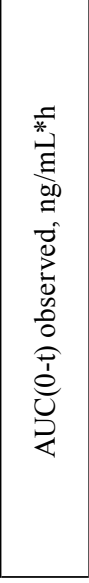 & 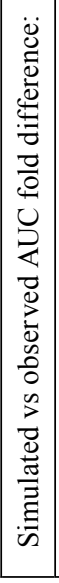 & 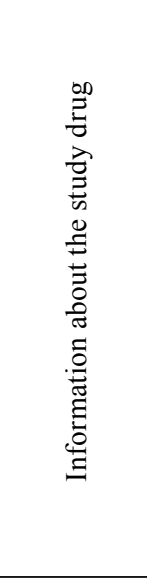 & 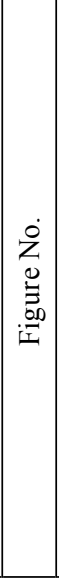 & 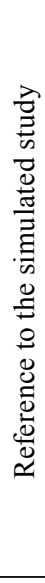 & 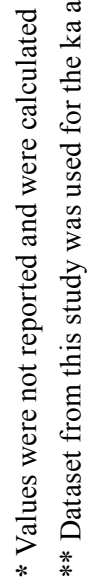 \\
\hline
\end{tabular}




\begin{tabular}{|c|c|c|c|c|c|c|c|c|c|c|c|c|c|c|c|c|c|}
\hline 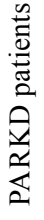 & 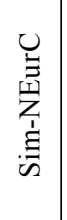 & $\begin{array}{l}\stackrel{0}{x} \\
\stackrel{x}{\simeq}\end{array}$ & 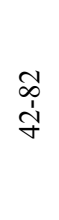 & $\because$ & 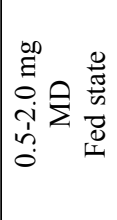 & $\stackrel{\cong}{\because}$ & $\nabla$ & 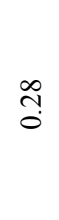 & ?f & 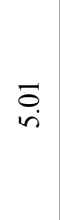 & तે & $\begin{array}{l}\stackrel{f}{\dot{F}} \\
\text {. }\end{array}$ & चें & $\stackrel{\circ}{-}$ & $\overleftrightarrow{z}$ & $\exists$ & $\stackrel{\mathscr{\rho}}{\varnothing}$ \\
\hline 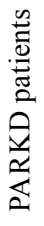 & 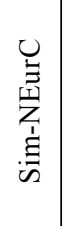 & $\begin{array}{l}\stackrel{0}{x} \\
\stackrel{x}{\simeq}\end{array}$ & 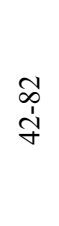 & $\because$ & 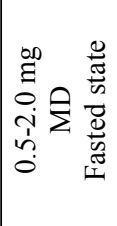 & $\stackrel{\infty}{\stackrel{\infty}{\longrightarrow}}$ & $\stackrel{\sim}{\dddot{c}}$ & $\stackrel{\text { ô. }}{-}$ & तु & గn & $\stackrel{8}{8}$ & $\begin{array}{l}\tilde{b} \\
\dot{q}\end{array}$ & $\overrightarrow{\mathrm{i}}$ & $\stackrel{\Xi}{-}$ & $\overleftrightarrow{z}$ & 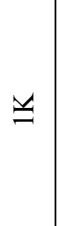 & $\underset{\infty}{\infty}$ \\
\hline 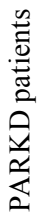 & 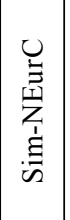 & 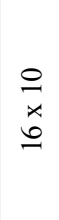 & $\begin{array}{l}\stackrel{n}{1} \\
\frac{1}{f}\end{array}$ & ڤై & 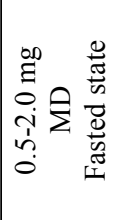 & $\stackrel{\infty}{\stackrel{\leftrightarrow}{-}}$ & $\stackrel{8}{-}$ & $\stackrel{\infty}{\stackrel{\infty}{\leftrightarrow}}$ & बें & $\stackrel{?}{\stackrel{f}{\sim}}$ & $\begin{array}{l}\vec{\infty} \\
0\end{array}$ & $\begin{array}{l}\stackrel{\infty}{1} \\
\infty \\
\infty\end{array}$ & $\stackrel{\sim}{m}$ & $\stackrel{n}{ت}$ & $\overleftrightarrow{z}$ & $=$ & 孚 \\
\hline 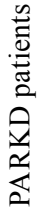 & 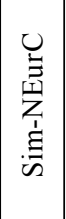 & $\begin{array}{l}\stackrel{0}{x} \\
\stackrel{x}{y} \\
\simeq\end{array}$ & $\begin{array}{l}\hat{0} \\
\frac{1}{n}\end{array}$ & $\stackrel{5}{0}$ & 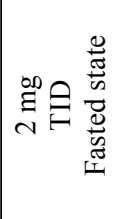 & 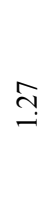 & $\underset{i}{\stackrel{\leftrightarrow}{i}}$ & 苞 & d. & $\begin{array}{l}b \\
i \\
i n\end{array}$ & $\hat{\sigma}$ & $\hat{\bar{m}}$ & $\stackrel{\vec{\lambda}}{\vec{v}}$ & $\stackrel{\text { qq }}{-}$ & $\overleftrightarrow{z}$ & $=$ & 寻 \\
\hline 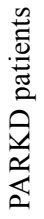 & 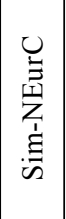 & $\begin{array}{l}\stackrel{\rho}{x} \\
\stackrel{x}{\varrho}\end{array}$ & $\begin{array}{l}\infty \\
\infty \\
\dot{1} \\
\dot{m}\end{array}$ & $\stackrel{0}{0}$ & 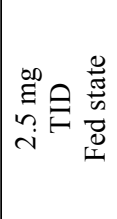 & $\begin{array}{l}\tilde{\delta} \\
\stackrel{0}{0}\end{array}$ & $\stackrel{\text { 尺 }}{\Xi}$ & $\begin{array}{l}\infty \\
\stackrel{0}{0} \\
0\end{array}$ & $\stackrel{\bar{n}}{n}$ & $\begin{array}{l}\vec{n} \\
\infty\end{array}$ & $\begin{array}{l}\infty \\
\infty \\
0 \\
0\end{array}$ & $\begin{array}{l}\stackrel{+}{n} \\
\stackrel{+}{ \pm}\end{array}$ & 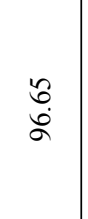 & 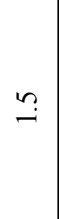 & 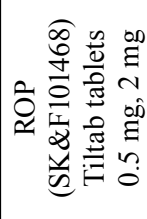 & $\Xi$ & $\widehat{\vartheta}$ \\
\hline 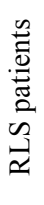 & 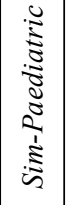 & $\begin{array}{l}\stackrel{\rho}{x} \\
x \\
\infty\end{array}$ & $\stackrel{\bar{\unlhd}}{\underline{I}}$ & $\tilde{n}$ & 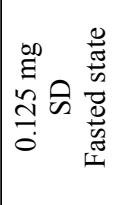 & $\stackrel{?}{\stackrel{2}{ت}}$ & $\stackrel{n}{i}$ & $\begin{array}{l}\infty \\
0 \\
0\end{array}$ & $\begin{array}{c}\text { ণิ } \\
\text { ô }\end{array}$ & 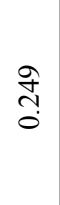 & $\begin{array}{l}\stackrel{\infty}{\circ} \\
\stackrel{0}{0}\end{array}$ & 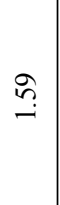 & 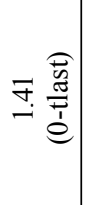 & $\stackrel{m}{=}$ & 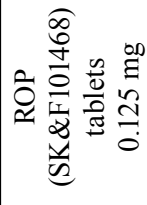 & $\underline{0}$ & Fิ \\
\hline 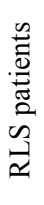 & 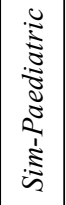 & 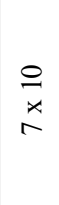 & $\stackrel{\check{I}}{\underline{\Xi}}$ & $\tilde{n}$ & 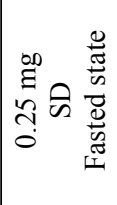 & 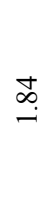 & $\stackrel{\infty}{-}$ & à & 京 & $\begin{array}{l}\infty \\
\stackrel{\infty}{0} \\
0\end{array}$ & $\begin{array}{l}\circ \\
\stackrel{0}{0}\end{array}$ & $\stackrel{\vec{m}}{=}$ & 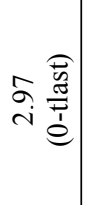 & $\stackrel{a}{-}$ & 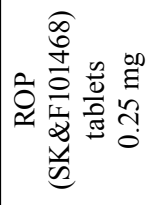 & 土 & Fิ \\
\hline 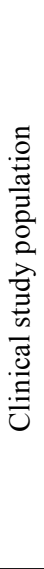 & 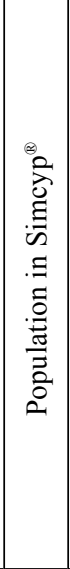 & 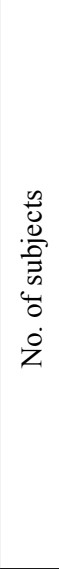 & 总 & 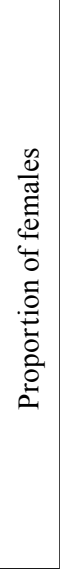 & 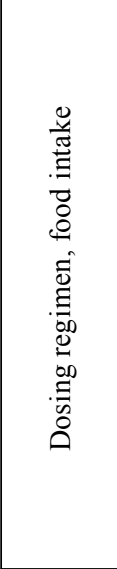 & 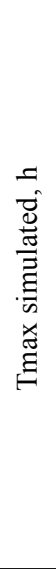 & 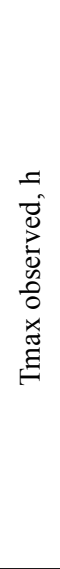 & 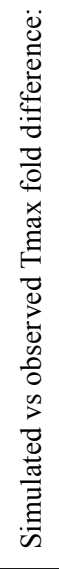 & 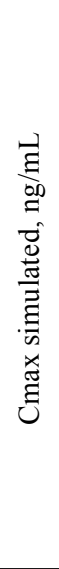 & 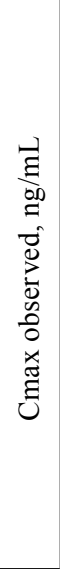 & 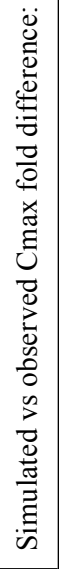 & 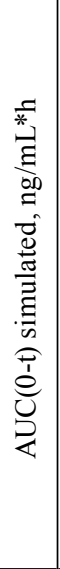 & 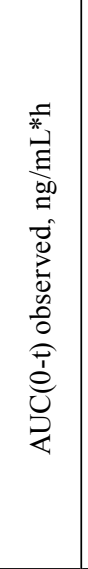 & 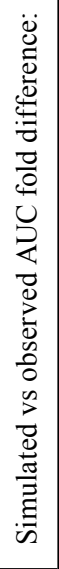 & 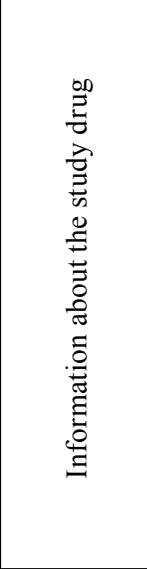 & 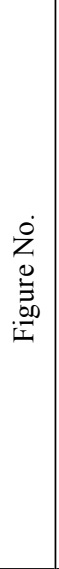 & 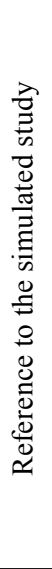 \\
\hline
\end{tabular}




\section{DISCUSSION}

The current study describes the development and verification of the PBPK model intended to predict the pharmacokinetics of the dopaminergic drug - ropinirole taken as an immediate release formulation. It should be noted that it is a well-established practice in PBPK, to begin with building a model based on studies for intravenous administration, however, such data for ropinirole was limited due to the poor tolerance of this drug (36). The only information available was from micro-dosing studies, which do not fully represent clinical conditions $(8,46)$. Therefore, the model was developed for the orally administered formulation with the immediate release based on data extracted from the relevant publications and clinical study reports which are listed in Table 2 and Table 3. Simulation performance was acceptable based on the criteria of a 2 -fold difference. The performance of the model is also demonstrated in Figure 1. The simulation of GSK study 218 (Figure 1M) has confirmed that the model has the capability to not only predict the same dose study but also reflects the ropinirole PK behavior during the whole titration regimen using multiple doses (study dose ranged from $0.25 \mathrm{mg} /$ day to $4 \mathrm{mg} /$ day). It can be noticed from Table 2 and Table 3 that healthy volunteers received lower doses $(0.25$ to $1 \mathrm{mg})$ as compared against PARKD patients ( 2 to $2.5 \mathrm{mg}$ ) which is a consequence of the fact that ropinirole is tolerated worse in healthy volunteers comparatively to PARKD patients.

Simulations of all the above-listed studies, including those conducted on patients, were carried out using healthy subjects' populations in Simcyp, without any modifications of the physiological parameters according to the disease state. The simulation results being very close to the clinically observed values suggest that ropinirole pharmacokinetics when it is administered as the immediate release tablets is not significantly affected by the neurologic disease or age-related factors and that it is generally consistent among healthy volunteers, RLS patients, and PARKD patients, which is in the agreement with the published data (37).

Among the simulated clinical studies, one study reported ropinirole PK in Chinese healthy volunteers. Despite the simulation results were in the range of 2-fold of the observed values, it can be seen from Figure $1 \mathrm{C}$ that the elimination phase is not properly captured by the model. Although more studies in this population are needed to make a conclusion whether it is a systematic deviation, we hypothesize that enzyme kinetic parameters used in the model development are not representative for in vivo metabolism kinetics in Chinese healthy volunteers.

The simulation of one of the studies in PARKD patients (38) failed to fulfill the 2-fold criteria in terms of Tmax. This may suggest that some physiological parameters that may differ between patients and $\mathrm{HV}$ and which influence ropinirole exposure during the long-term therapy are not accounted for in the current model. This point needs to be investigated further.

Ropinirole was also recently studied as a new therapeutic option in patients with prolactinomas (7). In addition to the clinical study, the researchers have developed a mechanism-based pharmacokinetic-pharmacodynamic model describing ropinirole and prolactin concentrations after single-dose administration in female patients with prolactinomas. We believe that our PBPK model could be used for the generation of input plasma concentrations for such a PKPD model, however careful investigation of pathophysiological parameters of patients with prolactinomas is needed.

Considering that ropinirole is cleared through CYP1A2- and CYP3A4-mediated metabolic pathways, the potential for CYP-mediated drug-drug interactions (DDI) arises. There is one clinical study of DDI between ropinirole and ciprofloxacin (47) which demonstrated a significant effect of the latter on ropinirole PK. Ciprofloxacin being an inhibitor of CYP1A2 produced a $60 \%$ and $84 \%$ increase in ropinirole's Cmax and AUC, respectively (2). The additional studies should be performed in order to model this interaction, which will allow to additionally verify the ropinirole mechanistic clearance model described in this paper.

\section{CONCLUSION}

In this study, we have developed and verified a PBPK model for the immediate release ropinirole tablets. The parameters of this model (e.g., distribution and metabolism) will serve as a base for further study in order to understand the behavior of the prolonged-release formulation in patient populations.

Limitation of the model. The current PBPK model was developed in order to gain a better understanding of ropinirole PK and is not intended for direct use in clinical conditions. The model can be further enhanced with the inclusion of patient 
population-specific physiological parameters and the incorporation of a more sophisticated absorption sub-model.

\section{Conflicts of interest}

Sebastian Polak and Zofia M. Bielecka are employees of Certara U.K. Limited, Simcyp division. Certara U.K. Limited had no role in the design of the study; in the collection, analyses, or interpretation of data; in the writing of the manuscript, or in the decision to publish the results.

\section{Funding}

The current project has been financed from the Polish National Science Center OPUS project number OPUS 2018/31/B/NZ7/03238.

\section{REFERENCES}

1. Deleu D., Northway M.G., Hanssens Y.: Clin. Pharmacokinet. 41, 261 (2002).

2. Kaye C.M., Nicholls B.: Clin. Pharmacokinet. 39, 243 (2000).

3. Chitnis S.: Expert Opin. Drug Metab. Toxicol. 4, 655 (2008).

4. de Biase S., Merlino G., Lorenzut S., Valente M., Gigli G.L.: Expert Opin. Drug Metab. Toxicol. 10, 1365 (2014).

5. Okano H., Yasuda D., Fujimori K., Morimoto S., Takahashi S.: Trends Pharmacol. Sci. 41, 99 (2020).

6. Fujimori K., Ishikawa M., Otomo A., Atsuta N., Nakamura R., et al.: Nat. Med. 24, 1579 (2018).

7. Liu S., Hu C., Peters J., Tsang A., Cremers S., et al.: Br. J. Clin. Pharmacol. 85, 366 (2019).

8. Ramji J.V., Keogh J.P., Blake T.J., Broom C., Chenery R.J., et al.: Xenobiotica 29, 311 (1999).

9. Bloomer J.C., Clarke S.E., Chenery R.J.: Drug Metab. Dispos. 25. 840 (1997).

10. Reavill C., Boyfield I., Coldwell M., Nelson P.: J. Pharm. Pharmacol. 52, 1129 (2000).

11. https://www.gsk-studyregister.com/en/ trial-details/?id=101468/061 (accessed on 19.04.2021).

12. Hubble J., Koller W.C., Atchison P., Taylor A.C., Citerone D.R., et al.: J. Clin. Pharmacol. 40, 641 (2000).

13. Tompson D., Oliver-Willwong R.: Clin. Neuropharmacol. 32, 140 (2009).

14. Vidailhet M.J., Bonnet A.M., Belal S., Dubois B., Marle C., Agid Y.: Lancet 336, 316 (1990).
15. Contin M., Lopane G., Mohamed S., CalandraBuonaura G., Capellari S., et al.: Parkinsonism Relat. Disord. 61, 111 (2019).

16. https://www.accessdata.fda.gov/drugsatfda docs/nda/97/020658_requip_toc.cfm (accessed on 19.04.2021).

17. https://www.accessdata.fda.gov/drugsatfda docs/nda/2008/022008_requip_toc.cfm (accessed on 23.03.2021).

18. https://www.gsk-studyregister.com/en/trialdetails/?id=101468/197 (accessed on 19.04.2021).

19. Jones H.M., Chen Y., Gibson C., Heimbach T., Parrott N., et al.: Clin. Pharmacol. Ther. 97, 247 (2015).

20. Rowland M., Peck C., Tucker G.: Annu. Rev. Pharmacol. Toxicol. 51, 45 (2011).

21. Nestorov I.: Expert Opin. Drug Metab. Toxicol. 3, 235 (2007).

22. Rostami-Hodjegan A., Tucker G.T.: Nat. Rev. Drug Discov. 6, 140 (2007).

23. Iwasaki S., Yamamoto S., Sano N., Tohyama K., Kosugi Y., et al. Pharm. Res. 36, 76 (2019).

24. Sawada Y., Hanano M., Sugiyama Y., Harashima H., Iga T.: J. Pharmacokinet. Biopharm. 12, 587 (1984).

25. Rodgers T., Leahy D., Rowland M.: J. Pharm. Sci. 94, 1259 (2005).

26. Adolph E.F.: Science 1109, 579 (1949).

27. Boxenbaum H.: J. Pharmacokinet. Biopharm. 10, 201 (1982).

28. Boxenbaum H., DiLea C.: J. Clin. Pharmacol. 35, 957 (1995).

29. Pang K.S., Rowland M.: J. Pharmacokinet. Biopharm. 5, 625 (1977).

30. Adlard M., Okafo G., Meenan E., Camilleri P.: J. Chem. Soc. Chem. Commun. 1995, 2241 (1995).

31. Coufal P., Stulík K., Claessens H.A., Hardy M.J., Webb M.: J. Chromatogr. B Biomed. Sci. Appl. 720, 197 (1998).

32. Swagzdis J.E., Wittendorf R.W., DeMarinis R.M., Mico B.A.: J. Pharm. Sci. 75, 925 (1986).

33. https:/www.ema.europa.eu/en/medicines/ veterinary/EPAR/clevor (accessed on 19.04.2021).

34. Yerramilli-Rao P., Beal M.F., Watanabe D., Kieburtz K., Blieck E.A. et al.: Int. J. Toxicol. 31, 58 (2012).

35. Arther R.G., Bowman D.D., Slone R.L., Travis L.E.: Parasitol. Res. 97 (Suppl 1), S76 (2005).

36. de Mey C., Enterling D., Meineke I., Yeulet S.: Br. J. Clin. Pharmacol. 1991 Oct;32(4):483 (1991). 
37. https://www.gsk-studyregister.com/en/trialdetails/?id=101468/218 (accessed on 19.04.2021).

38. Brefel C., Thalamas C., Rayet S., Lopez-Gil A., Fitzpatrick K., et al.: Br. J. Clin. Pharmacol. 45, 412 (1998).

39. Wen A.-D., Jia Y.-Y., Luo X.-X., Bi L.-L., Chen X.-Y., Zhong D.-F.: J. Pharm. Biomed. Anal. 43, 774 (2007).

40. https://www.gsk-studyregister.com/en/trialdetails/?id=101468/161 (accessed on 19.04.2021).

41. https://www.gsk-studyregister.com/en/trialdetails/?id=101468/198 (accessed on 19.04.2021).

42. https://www.gsk-studyregister.com/en/trialdetails/?id=101468/253 (accessed on 19.04.2021).
43. https://www.gsk-studyregister.com/en/trialdetails/?id=101468/164 (accessed on 19.04.2021).

44. Thalamas C., Taylor A., Brefel-Courbon C., Eagle S., Fitzpatrick K., Rascol O.: Eur. J. Clin. Pharmacol. 55, 299 (1999).

45. Taylor A.C., Beerahee A., Citerone D.R., Cyronak M.J., Leigh T.J., et al.: Pharmacotherapy 19, 150 (1999).

46. https://www.gsk-studyregister.com/en/trialdetails/?id=101468/009 (accessed on 19.04.2021).

47. https://www.gsk-studyregister.com/en/trialdetails/?id=101468/102 (accessed on 6.05.2021).

(C) 2021 by Polish Pharmaceutical Society. This is an open-access article under the CC BY NC license (http://creativecommons.org/licenses/BY/4.0/). 